\title{
E-Learning Tool for Digital Design and Embedded System Training
}

\author{
Giuliano Donzellini and Domenico Ponta \\ DIBE - Department of Biophysical and Electronic Engineering, \\ University of Genoa, Genova, \\ Italy
}

\section{Introduction}

The complexity of today's digital systems is putting new demands on the education of the professionals working in this field. Electronic Design Automation (EDA) techniques are the core of digital systems development processes, while traditional design and prototyping have lost their roles. EDA techniques are finding their way in engineering education: professional tools are available at very favourable conditions for educational institutions, and successfully used in engineering courses.

In our opinion, the use of a professional simulator in a course designed to provide the foundations of digital design is not yet a good choice. A tool conceived to increase the productivity of a digital designer does not meet, albeit as its primary target, the needs of education. What is a plus for the professional (for instance the wide availability of components and functions) may be a minus for the learner.

Another noticeable aspect of digital design education is related to the introduction of Hardware Description Languages (HDL). A growing number of teachers introduce HDL and EDA tools in basic, introductory courses: but beginner students do not possess the skills and the frame of mind of the professional designers. Moreover, the use of HDL for design could be an handicap when the learner lacks programming experience and the high level of abstraction that is required to successfully use HDL. We suspect that the use of professional tools and HDL in introductory courses may hide from learners important basic issues. Nevertheless, to achieve some familiarity with EDA techniques is a necessary target of a digital design course, even an introductory one.

The growing diffusion of Internet have deeply influenced the framework of engineering education, and has shifted the attention toward applications focused on communication and cooperation (Ponta \& Scapolla, 2007). Moreover, Internet-controlled remote laboratories for electronics are now available from many educational institutions, and the concept of executing experiments remotely is a consolidated practice (Bagnasco et al., 2005; Asumadu et al., 2005; Zimmer et al., 2006; Gustavsson et al., 2006; Donzellini \& Ponta, 2007, a). The use of PLD-based boards (Garcia-Zubia et al., 2006) allows to setup remote labs for digital electronics dealing with relatively complex digital systems. 
In the past, the authors have employed hypertexts, author languages and multimedia materials to develop highly interactive learning tools to form a learning environment for electronics (Da Bormida et al., 1997). The pedagogical results suggested that a general purpose simulator would advantageously substitute the entire set of interactive tools. In the following we will use the expression "virtual laboratory" to refer to a set of learning material and software tools simulating the functionalities of a traditional laboratory. Virtual laboratories for digital electronics are based either on professional applications, or simulation tools designed for educational purposes (some commercial and non-profit products, often used in the educational field, are listed in the Appendix).

Commercial simulators usually lack the capability to interact with learning material, being oriented to professional users that already possess the proper frame of mind and the skills that students of introductory courses cannot yet master. We considered the possibility of adopting a professional simulation tool but, at the end, we decided to develop our own environment integrating simulation features with tutorial materials.

This is the foundation of the Deeds (Digital Electronics Education and Design Suite), a virtual laboratory for educational application (Donzellini \& Ponta, 2007, b) available at http://www.esng.dibe.unige.it/deeds.

\section{E-learning with the Deeds environment}

The design and simulation suite that we developed, Deeds, represents our approach to foster learning of digital design. Our target is to prepare students to the use of current and future EDA tools by building a solid understanding of the principles of digital design. This means to guide a learner, with no previous knowledge, typically in a one year long course, to achieve the foundation for designing embedded systems.

The experience of the authors in the educational use of Deeds dates from several years ago, when the first versions of the simulators were released (Bovone et al., 1999; Ponta et al., 2001; Donzellini \& Ponta, 2003). Deeds functionalities and pedagogical applications have co-evolved in close contact, since the technical evolution of the tools has been dictated, mainly, by the needs emerged during the educational practice. In our university, Deeds is extensively used by the students of the first and second year of electronic and information engineering to support laboratory activity and project-bases courses.

NetPro (Ponta et al., 2001; Markkanen et al., 2001), an European project of the Leonardo DaVinci programme, running from 1997 to 2003, has served as a catalyst and support for the development of the Deeds toward its current architecture. Deeds is a set of Windows ${ }^{\circledR}$ applications, developed in Delphi®), to be installed on the user's personal computer. Deeds is available, from its web site, free of charge to all interested users.

The suite is composed by three simulators and a wide collection of associated learning material to practice with: combinational and sequential logic networks, finite state machine design, embedded microcomputer interfacing and programming. These tools are characterised by a "learning-by-doing" approach and can run independently or in connection with web repositories of learning material. The environment itself can be looked at from two different points of view: either as learning materials that includes general simulation capabilities or as a simulator capable of delivering learning contents. This makes possible to understand the interaction between hardware and software components of 
embedded systems, a subject that is receiving a growing attention from the engineering education community (Bruce et al., 2004; Nooshabadi \& Garside, 2006).

Deeds-based embedded systems, in spite of their apparent simplicity, provide a good understanding of the interaction and trade-off between hardware and software, building the skills that are at the base of current state-of-the-art implementations. The growing complexity of current embedded systems calls for the use of embedded platforms and highlevel languages for their design. This process, inevitably, shifts the focus of attention toward designing at system level and rightly suggests a top-down approach. The authors are convinced that, to found the education of the professional designer of embedded systems, a bottom-up path, such the one provided by Deeds, plays an essential role.

Deeds is, by its own conception, a suite of tools aimed at the basic understanding of projects including both aspects of hardware and software, since the logic simulator can handle a system composed of standard digital components, state machines and microcomputers, as it is the case in contemporary digital design. Deeds allows a total control, at low level, of the interaction between logical circuits behaviour and the procedural flow of machine level instruction execution of a microcomputer. The pedagogical aim of this approach is the understanding of many issues characterizing embedded systems, like microcomputer interfacing, interrupt handling, real time operation and trade-offs between hardware and software, as a foundation for more advanced digital design courses. From this point of view, the inclusion of specific tools for hardware-software co-design and platform oriented design goes beyond the purposes of the current development phase of Deeds.

The Deeds simulators can be used stand-alone or in conjunction with its specialized web browsers or with any other standard browser: the student access from its Internet site pages with information, lessons, exercises and laboratory assignments. The available learning material is designed to help students to acquire the theoretical foundations of digital design, together with analysis and problem-solving capabilities and practical synthesis and design skills. Deeds can be adapted to different formats of instruction (lectures, exercises, lab assignments, etc.) and can be delivered at different student levels. To do so, teachers can combine together and personalize the available simulation tools to suit their pedagogical needs by contributing to the lecture space their own learning materials (the lecture space can be composed with any web page editor).

The more exhaustive pedagogical experimentation of Deeds has been made in what is called a "blended" environment, a pedagogical situation where traditional lectures coexist with some form of distance learning. According to (Gillet et al., 2005), blended learning favours the evolution from traditional teaching to active learning, a target the authors are looking forward to. Currently, the Deeds laboratory is used in a PC classroom, with tutorial assistance, and in distant mode, through Internet. Both scenarios are supported by Moodle (http://www.moodle.org), the Learning Management System (LMS) adopted as a standard by the University of Genoa (http://www.aulaweb.unige.it), as well as many other universities worldwide.

The integration of Deeds with a LMS provides added value for teachers and students alike. The LMS guides students, at the beginning of each course, to install Deeds and then provides, as resources, a set of guided laboratory sessions.

Teachers can easily keep track of students' activity, provide news and guidance, have access to the project deliverables and, generally, take advantage of the LMS features to manage the course. Students gain a large amount of flexibility in the execution of the projects, and they 
can exchange information with their peers and get help by the teachers through the discussion forums.

Deeds e-learning features are intrinsic to its main characteristic, i.e. the close association of the simulators with on-line learning material, obtained through the web browser. A large repository of problems is available, with total freedom of navigation among individual problems, on the Deeds web site.

Deeds presents a project as a web document with text, figures and other visual objects that can be active, i.e. working as commands to the editing and simulation tools (see Figure 1). When the user clicks on the schematic in the browser, Deeds launches the corresponding simulator, and opens that schematic in it (Donzellini \& Ponta, 2008). If guidance is needed, the Deeds opens another page in another browser that may provide more information on how to design, explore or test the circuit itself.

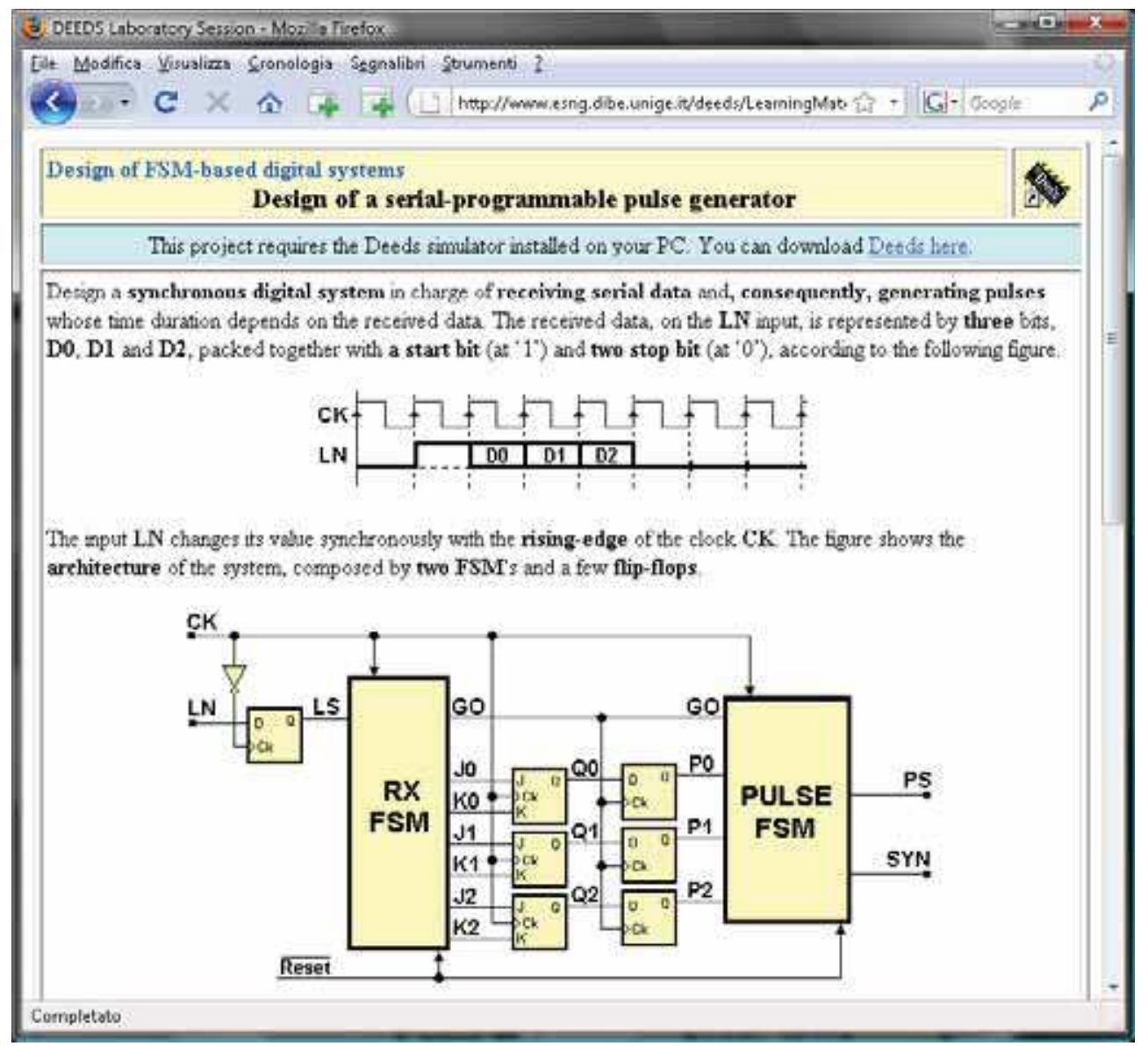

Fig. 1. An example of Deeds project (available at Deeds web site) 
The target of traditional exercises is to help students understanding the underlying theory. Usually a feedback from the teacher on the correctness of the solutions is necessary. A Deeds exercise, instead, it is always a project. The students' role is not only to work out a solution but, also, to check its correctness, i.e. its consistence with the project specifications. Teacher's feedback becomes, if not irrelevant, at least not essential for the students, since they must know by themselves if their work is correct. The above is the most important advantage of developing a project with the support of a simulation tool.

Usually a lab report on the project is requested: a proper template speeds up its preparation and allows the student to concentrate more in the technical work. When learners are satisfied with their work they use Deeds to deliver the reports through the LMS and Internet. Another important features of Deeds, making it more flexible in facing students of different technical levels, is the ability to deliver a suitable trace of the solution (i.e. a partial schematic of the solution). Using this approach, students can be guided to the desired level of problem solving, for example avoiding repetitive tasks.

Deeds learning materials, by default written in English, have been translated in other languages by the interested teachers, when they believed a presentation of the projects in the pupils' mother tongue would improve the pedagogical effectiveness.

Subsets of learning materials are therefore available in Italian, Catalan and Finnish languages, while an almost complete collection in Turkish can be found at: http:// portal.cizgi.com.tr/library/topic.aspx?id=1131.

\section{The Deeds simulators}

The simulators upon which the Deeds environment is based are: the Digital Circuit Simulator (d-DcS), the Finite State Machine Simulator (d-FsM) and the Microcomputer Emulator (d-McE). This paragraph contains a short introduction to their features. Practical examples of their use are contained in the next section, presenting step by step the student's activity for the development of a project assignment on embedded system design.

The d-DcS is similar to a professional digital simulator but has been specifically developed with educational needs in mind and, therefore, is characterised by a very simple and intuitive user interface and a rational choice of digital components available. The user can design custom components for the d-DcS as finite state machines using the proper tool, the $\mathrm{d}$-FsM. The most complex components of the d-DcS library is a 8-bit microcomputer for embedded applications, that can be connected through standard input-output parallel ports. The firmware must be programmed at machine language level using the $\mathrm{d}-\mathrm{McE}$ tool.

The simulation is event-driven, and includes the delay times of components. In the "animation" mode, the student can observe the behaviour of a network in term of static logic values by applying inputs with mouse clicks. In the timing diagram mode, a window shows the simulated outputs resulting from a set of input stimuli (graphically defined by the user). This mode is the same one adopted by professional simulators.

The d-DcS feature that allows the saving of input signal sequences provides further pedagogical advantages: teachers can propose one or more meaningful sets of input sequences, included in the same circuit schematic file. In addition to system specifications expressed by text, the teacher can provide the appropriated input sequences against which testing the implementations, including them into the solution trace. Not to be overlooked, is 
the fact that, when delivering a solution to the teacher, students can demonstrate their awareness of the circuit functionality by proposing reasonable input test sequences.

Graphical editing and simulation of FSM components, using the ASM (Algorithmic State Machine) paradigm are the domain of the d-FsM tool, which is able to functionally simulate the FSM designed by the user, with runtime display of the relations between states and time evolution. The components created by the d-FsM can be used in the d-DcS and inserted into the digital circuit schematic. Also, the d-FsM tool can export its files describing FSM as VHDL processes, allowing their reuse in professional design tools.

With the third simulator, $\mathrm{d}-\mathrm{McE}$, the user can practice microcomputer programming at assembly language level. The emulated system includes a CPU, ROM and RAM memory banks, parallel I/O ports, reset circuitry and a basic interrupt logic. The custom 8-bit CPU, the DMC8, has been designed to suit the educational needs of an introductory course, and it is based on a simplified version of the 'Z80-CPU' processor. The complex architecture of today's CPU's does not suggest the use of a contemporary device to understand the basic principles of machine-level programming.

The user enters the source code in the editor, and then assembles, links and loads it in the emulated system memory. The execution of the programs takes place in the debugger, where the user can check all the structures involved in the hardware/software system: ROM and RAM memory contents, I/O port state, CPU registers and the assembly code in execution.

\section{Introducing embedded system design: a project assignment example}

To understand and design embedded systems with a bottom-up approach, students need to familiarise themselves with analysis and design of systems based on standard logic circuits, finite state machines and microcomputers. We believe that the task of introducing embedded systems can be made easier by starting with the analysis of a pedagogicallyoriented implementation, before attempting the design.

In this section, we present, step by step, a learning process where students are facing a mixed work of analysis of the hardware structure and design of the microcomputer controlling software of a simple embedded system.

The system chosen for the project is an Asynchronous Serial Data Receiver/Transmitter, were the embedded microcomputer buffers and encrypts data. This project is included in the learning material available at http://www.esng.dibe.unige.it/deeds, see Figure 2.

In the project assignment (Figure 3), the system hardware is given and explained; the student must complete the system by writing the control software. The pedagogical target is to understand dynamics and interactions among modules of an interrupt-driven embedded system.

In the following, we describe the process from the students point of view. We assume that, formerly, they have become familiar with analysis and design of systems based on standard logic circuits, finite state machines and a microcomputer, as the knowledge and skills gained in the previous phases are necessary to understand and design embedded systems, in a bottom-up approach. 


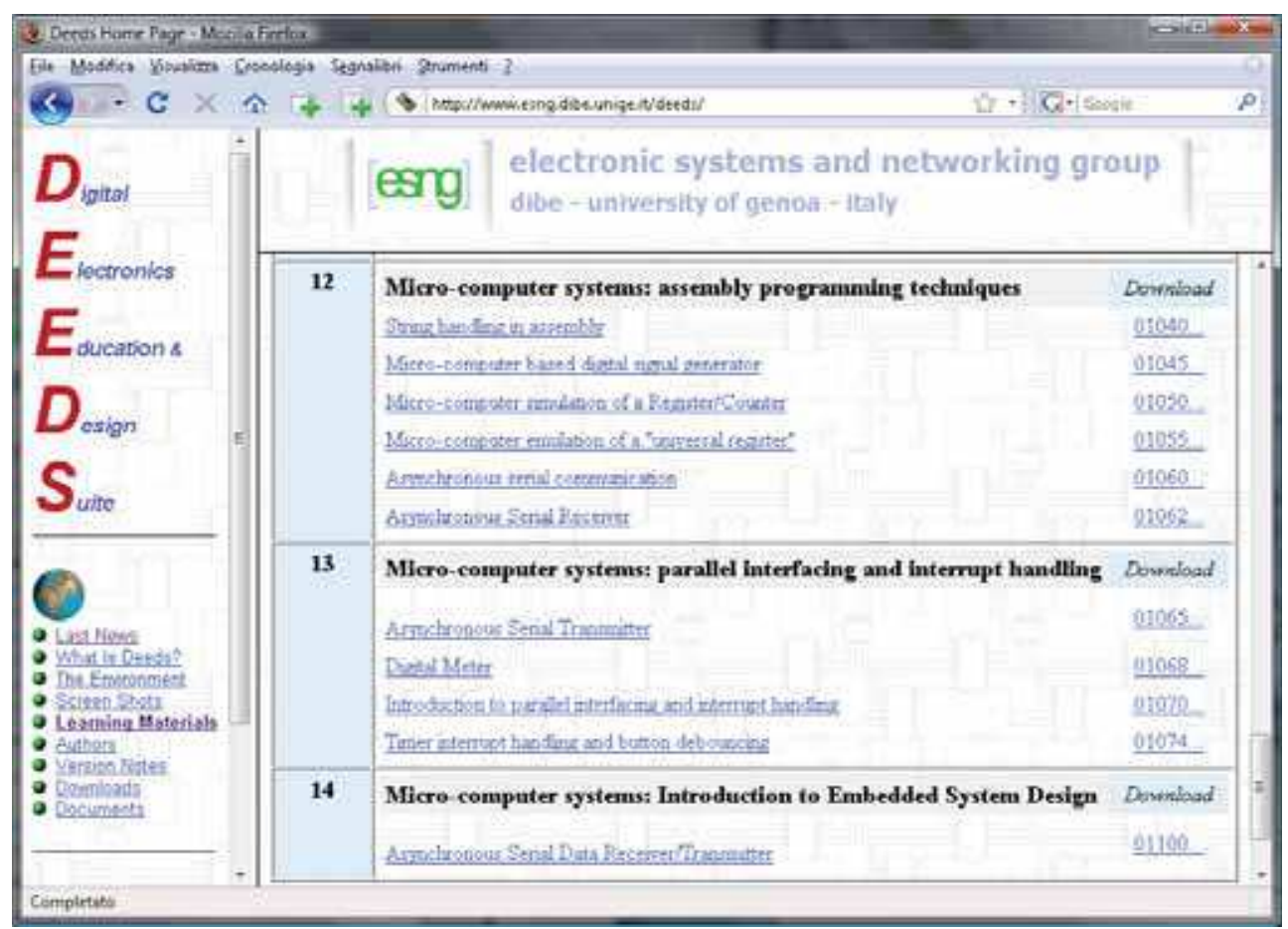

Fig. 2. The Deeds collection of learning material

In Figure 3, the project assignment is opened in the web browser. The text describes the overall system, explaining to the students that they will face a mixed work of analysis of the hardware structure and design of the microcomputer controlling software.

The data processing path include a receiver and a transmitter that are implemented by hardware, while the micro-computer, in the middle, has the task of buffering and processing data via software. The interrupt logic module is well in evidence in this figure, because this project deals specifically with dynamics and interactions among modules of an interruptdriven system.

In the next step, the asynchronous serial receiver is explained to the student (see Figure 4). Similar networks have been already encountered and analysed by students in previous projects, developed in the course of the learning process. To be more incisive, the receiver has been separated from the overall system and presented as a stand-alone module.

The receiver system is built around a sequencer controlling a counter and a shift register. The peculiarity of the circuit consists in the interaction between the standard hardware (the counter and the shift register) and the sequencer, that has been designed according to the FSM model. The text suggests to open another web page, where the controller unit algorithm is described in detail, in the format of ASM diagram (see Figure 5). 


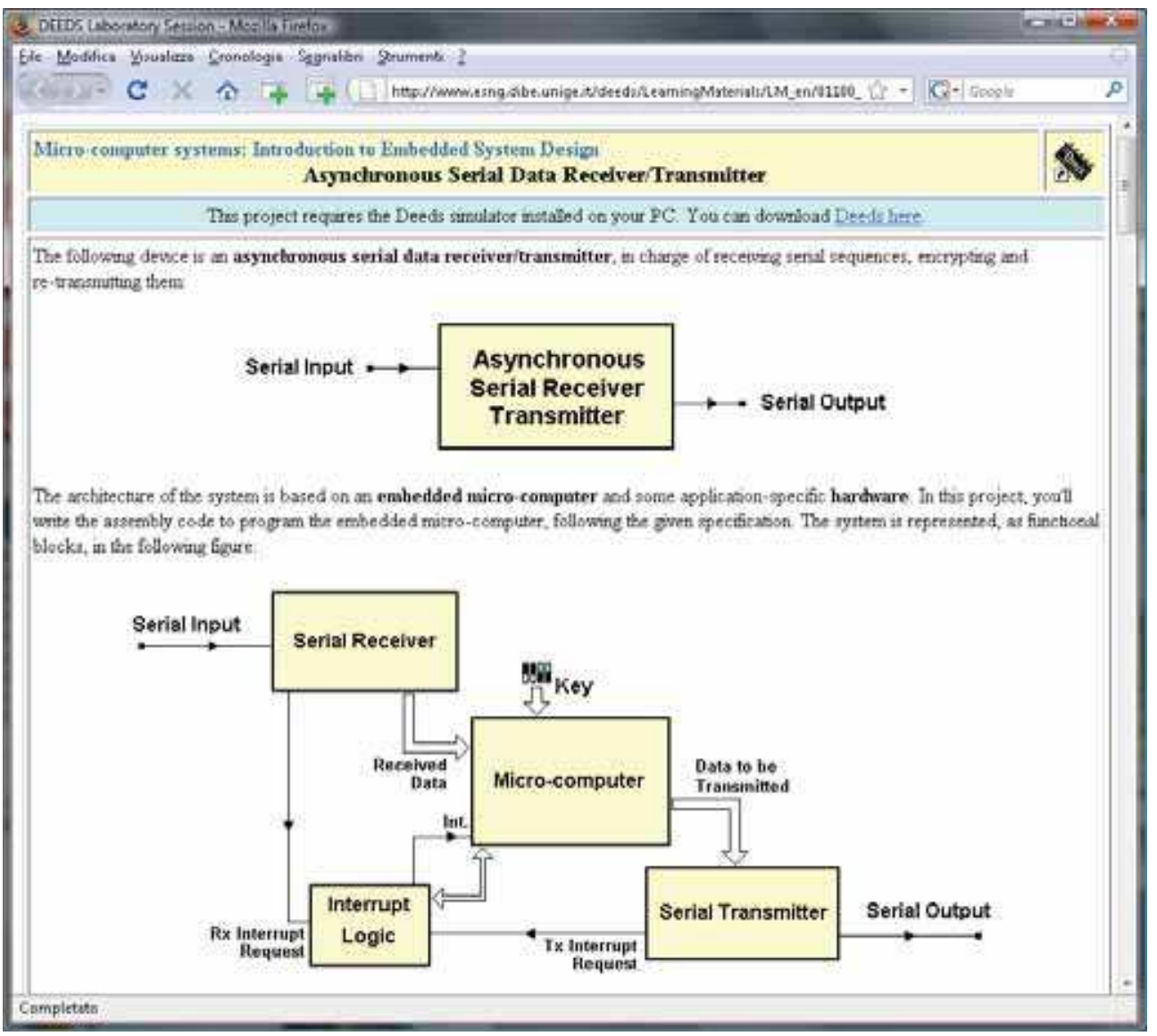

Fig. 3. The embedded system project assignment

The text description of the algorithm is exhaustive but, of course, the best approach available to the student is to open the ASM diagram in the finite state machines simulator and experience directly its behavior. In fact, for a full understanding, it is essential to look at the state diagram together with the time evolution of the signals of the control unit.

With a click on the ASM diagram of Figure 5 the learner finds it opened in the d-FsM and can check its operation with the tool (see Figure 6). The timing diagram is interactive: single clock cycles can be generated and input signals can be changed in between. The current state is highlighted on the ASM diagram, too, facilitating the observation of the evolution of the FSM in the state and time domain at the same time.

The complete circuit of the serial receiver module can, of course, be opened in the digital circuit simulator (see Figure 7), again with a click on the schematic. 


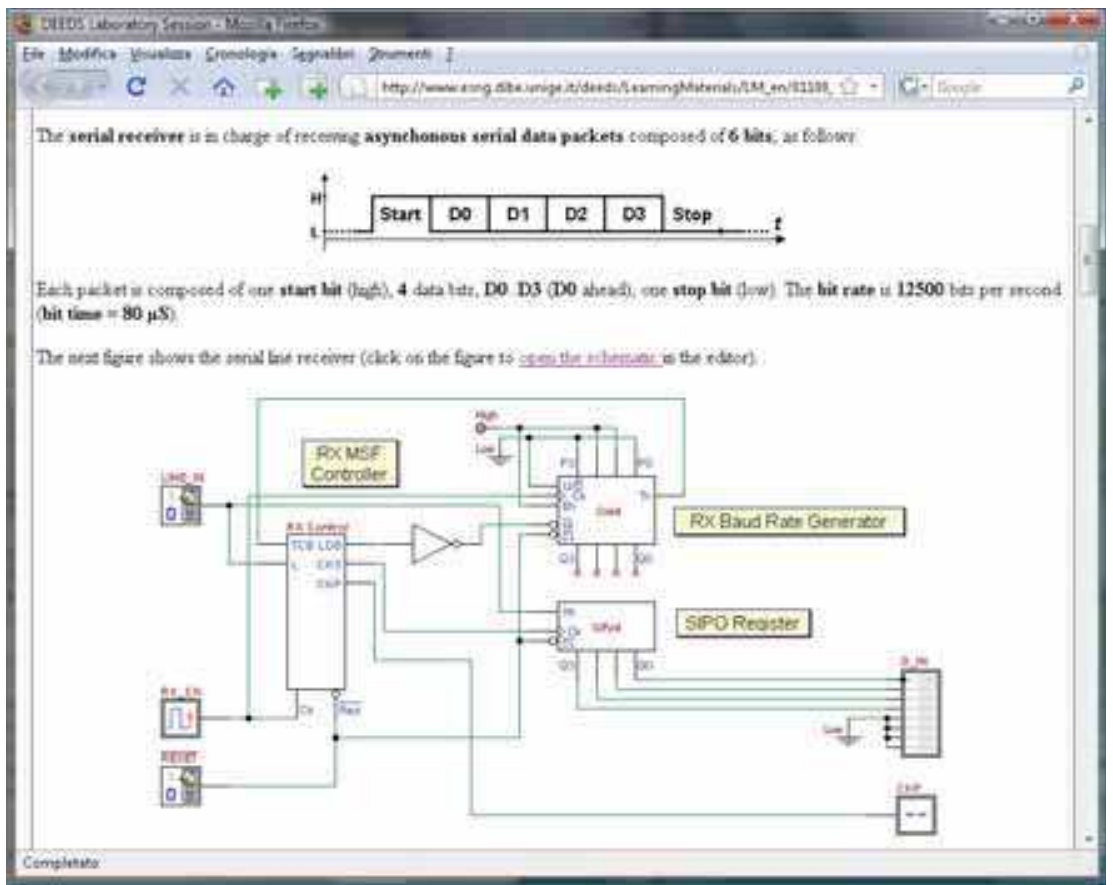

Fig. 4. The asynchronous serial receiver module

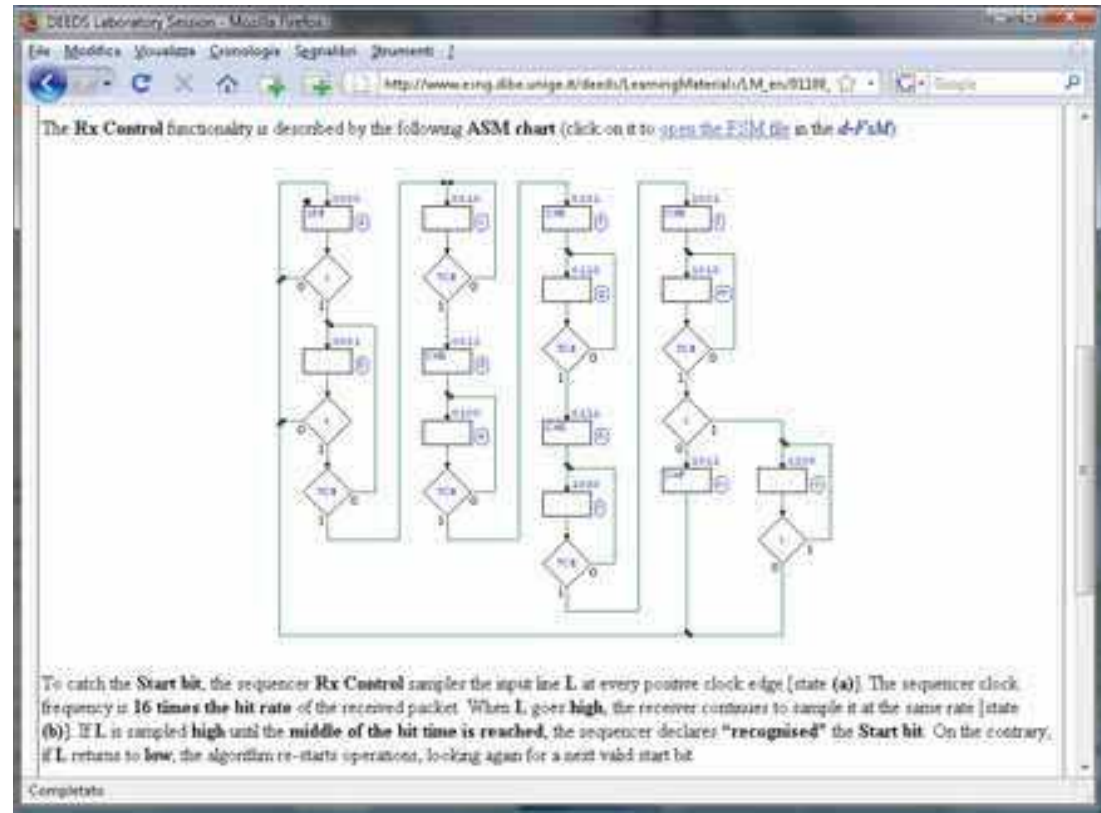

Fig. 5. The ASM description of the control unit of the serial receiver 


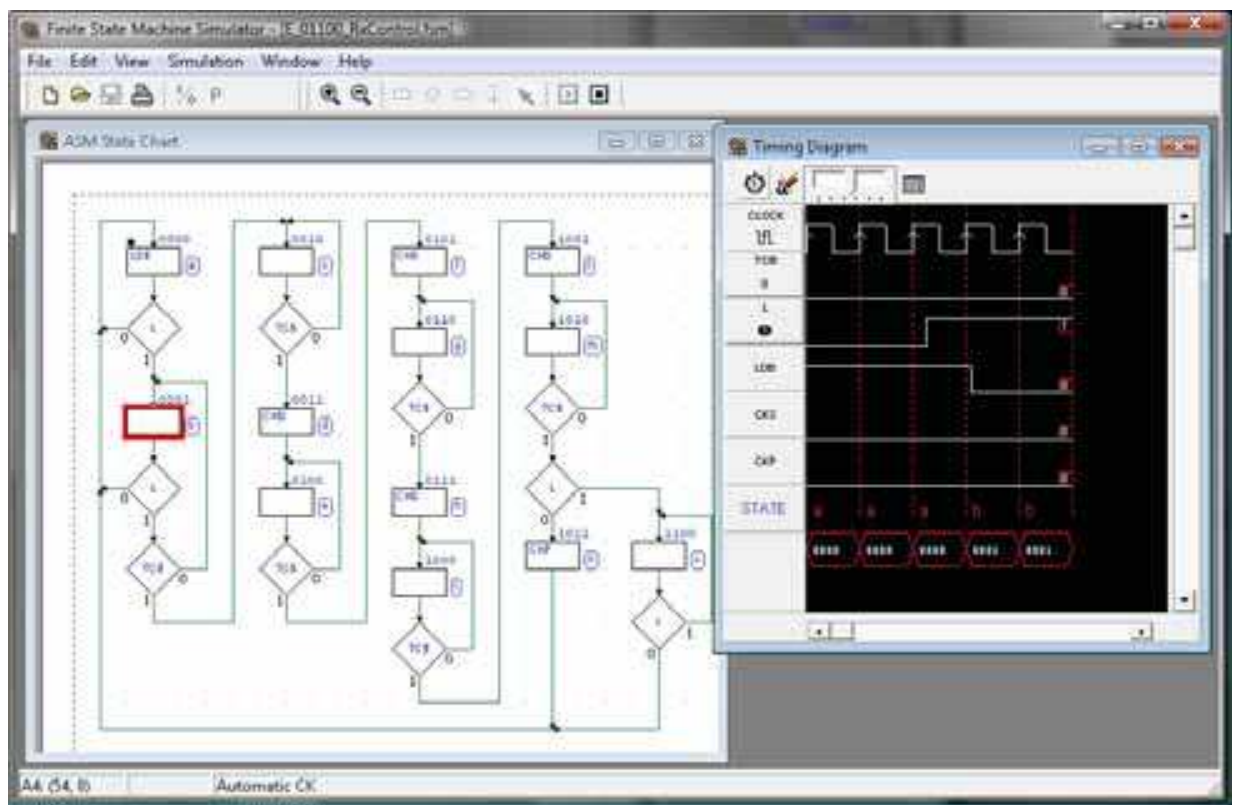

Fig. 6. The d-FsM during an interactive session.

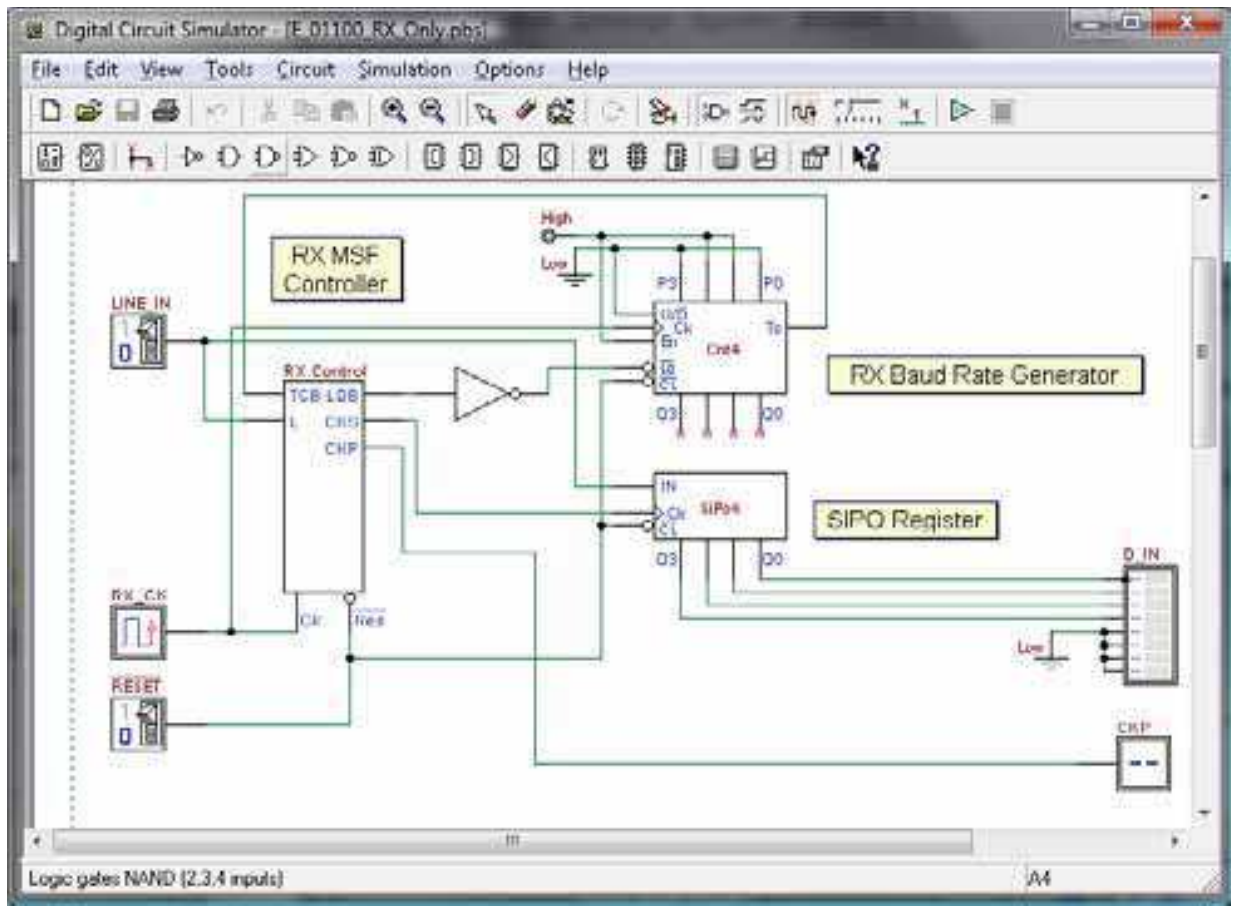

Fig. 7. The asynchronous serial receiver module opened in the d-DcS 


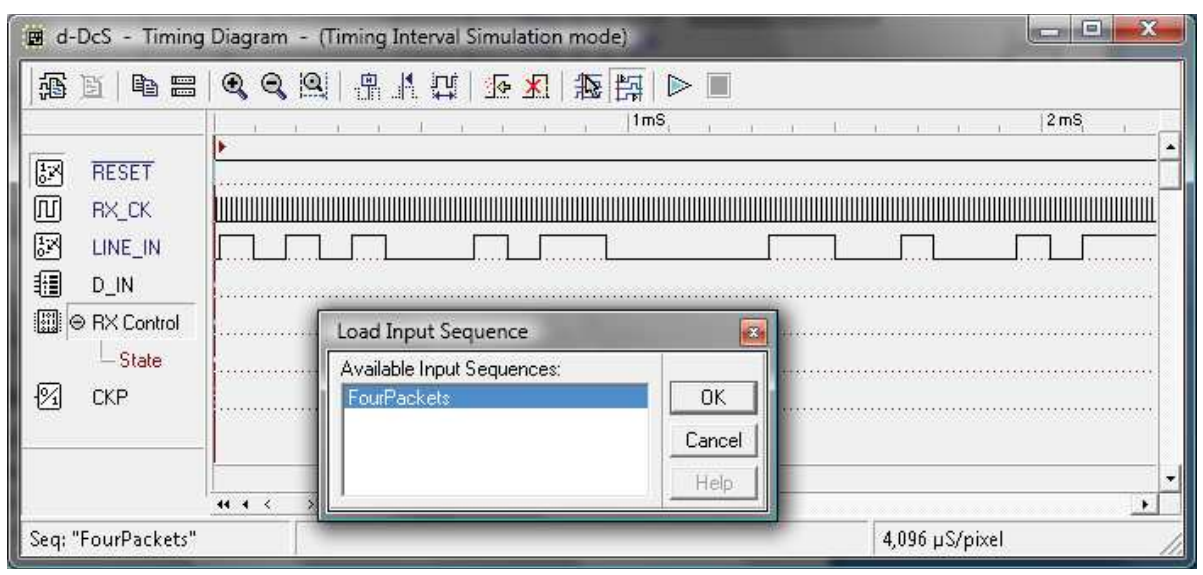

Fig. 8. The timing diagram of the d-DcS and the choice of the test sequence

The possibility, already mentioned, to make available to the learner packages of input sequences prepared by the teacher is especially useful in this particular case (see Figure 8). In fact, to set up an exhaustive test sequence is not a trivial task for a student and such feature may be of great help, since input stimuli can be used as they are or can be modified by the more adventurous students.

Simulation results can be analysed in the timing diagram, where it is possible to select areas of interest and expand the scale to compare the states and signals evolution with the one expected in the previous design phases. Specialized cursors provide useful features, such as measuring the time span between two events (see Figure 9).

Next, the assignment explains, with criteria similar to the ones used for the receiver block, the asynchronous serial transmitter module. The control unit, in this case also, is designed as FSM. The student can perform the analysis of the serial transmitter module with the d-FsM and the d-DcS simulator, as in the previous module. In Figure 10 the transmitter is opened in the d-DcS.

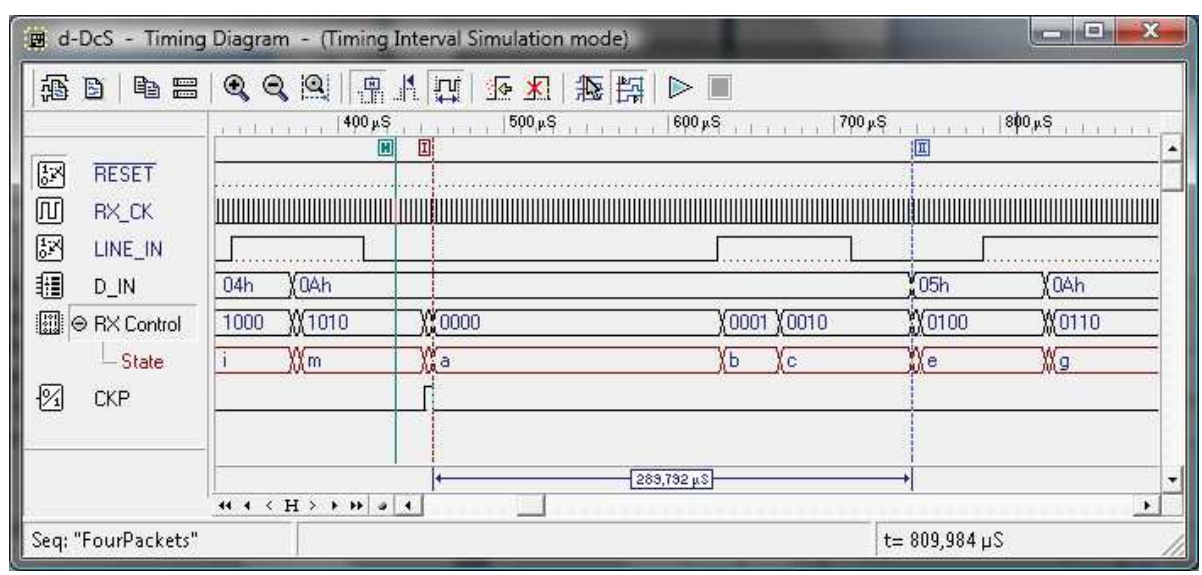

Fig. 9. Analysis of the simulation results in the timing diagram 


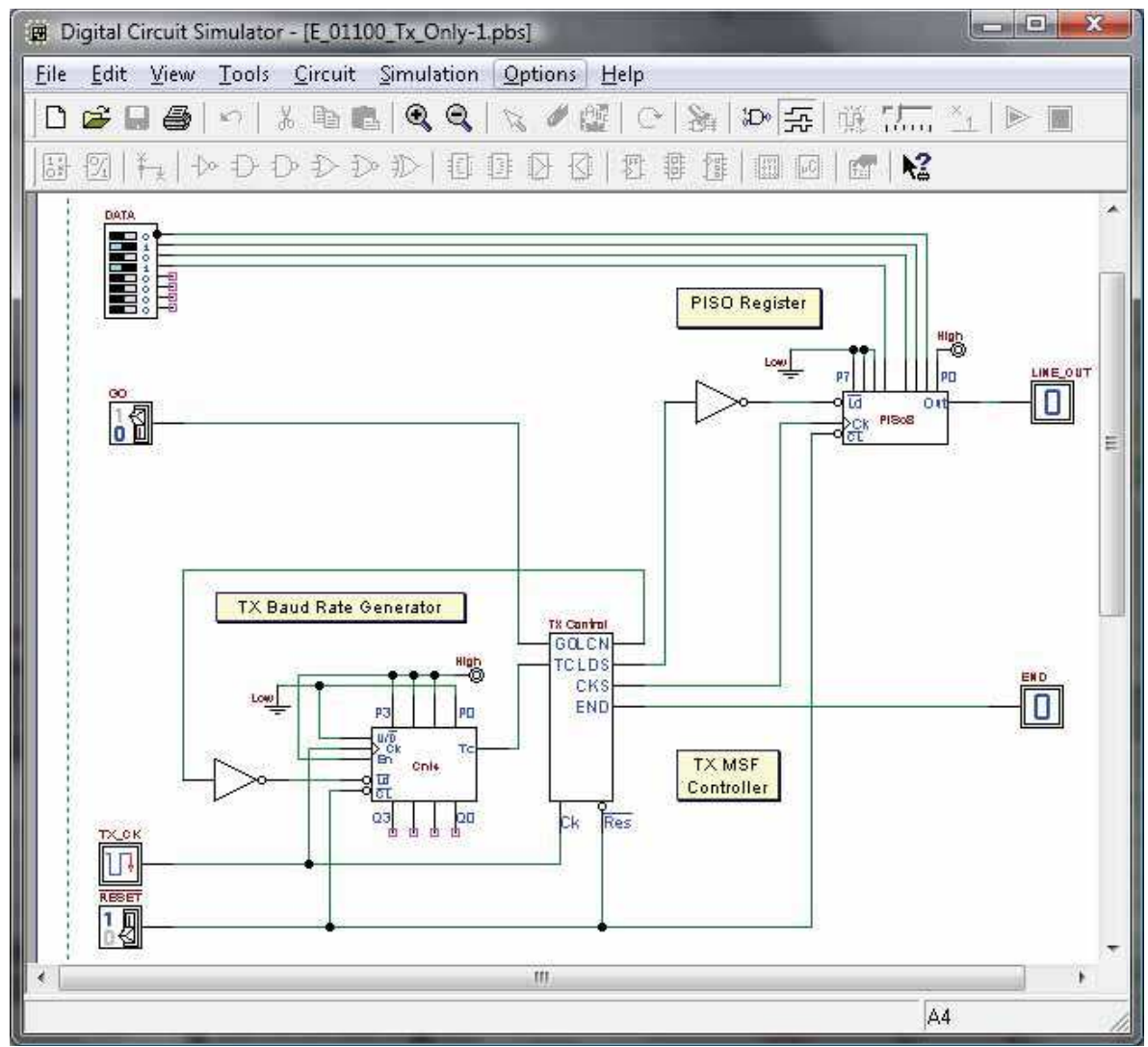

Fig. 10. The asynchronous serial transmitter module opened in the d-DcS

The analysis of the transmitter is particularly interesting from a pedagogical point of view, because the design issues are similar as far as the method is concerned, but very different in term of specifications. In short, the analysis of the receiver highlights the problems of synchronization and decoding of asynchronous data, while the analysis of the transmitter focuses on data coding and timing.

The assignment presents the whole system as a large schematic, whose divisions into functional blocks are highlighted (Figure 11). In the figure, besides of the receiver and transmitter modules (marked as RX and TX), are identified the embedded micro-computer $(\mathrm{MC})$, that links the receiver and transmitter modules, controlling the data flow, and the interrupt logic block (IL), a key element of the project.

If the student clicks on the figure, this schematic is opened in the d-DcS, but it cannot be simulated yet, because it is incomplete: the microcomputer ROM memory needs to be programmed with the code written by the student. We can say that, from a pedagogical point of view, all the previous activities are only a preparation to the real work, that is beginning now. 


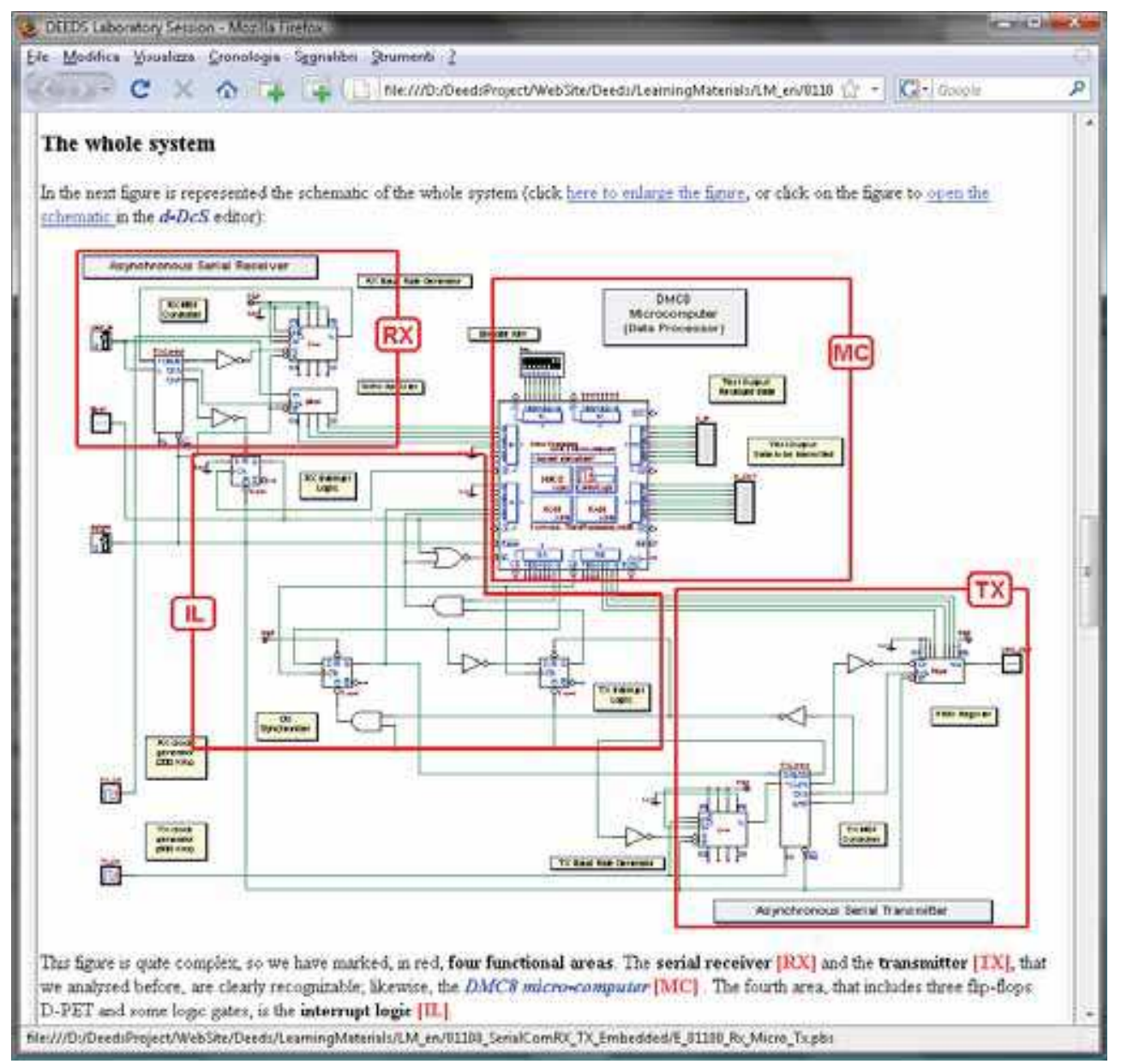

Fig. 11. The assignment description of the complete system

Now it is the moment to understand how the embedded microcomputer should act efficiently to process the data incoming from the receiver module and then send information to the transmitter, avoiding timing and logical conflicts.

The understanding of the interrupt controller logic behaviour is essential for developing the micro-computer program, so the text explains the purpose and operation of this logic block, that is composed by two parts, one devoted to the receiver, the other to the transmitter.

Starting with the receiver, the student should be aware that this logic acts as a functional bridge between the module and the microcomputer. In Figure 12 the logical path, involved in this operation, is highlighted and explained to the learner.

The interrupt controller signals to the microcomputer when new data has been received, activating its interrupt request line. Since the interrupt request line is a shared resource, the microcomputer must control if the receiver (or the transmitter, or both) has requested attention. So the student should realize that, before reading the received data (using the 
input port IB, Figure 12), the software must read the input port IA, where all the interrupt requests are conveyed, to identify the source of interruption.

Finally, the learner will be aware that the logic has been designed mainly to speed up the microcomputer operations. To do so, the reading of the input port IB, in addition to simply bringing up the desired data, also will clear the receiver interrupt logic, allowing the receiver module to be able to decode new data incoming from the input serial line.

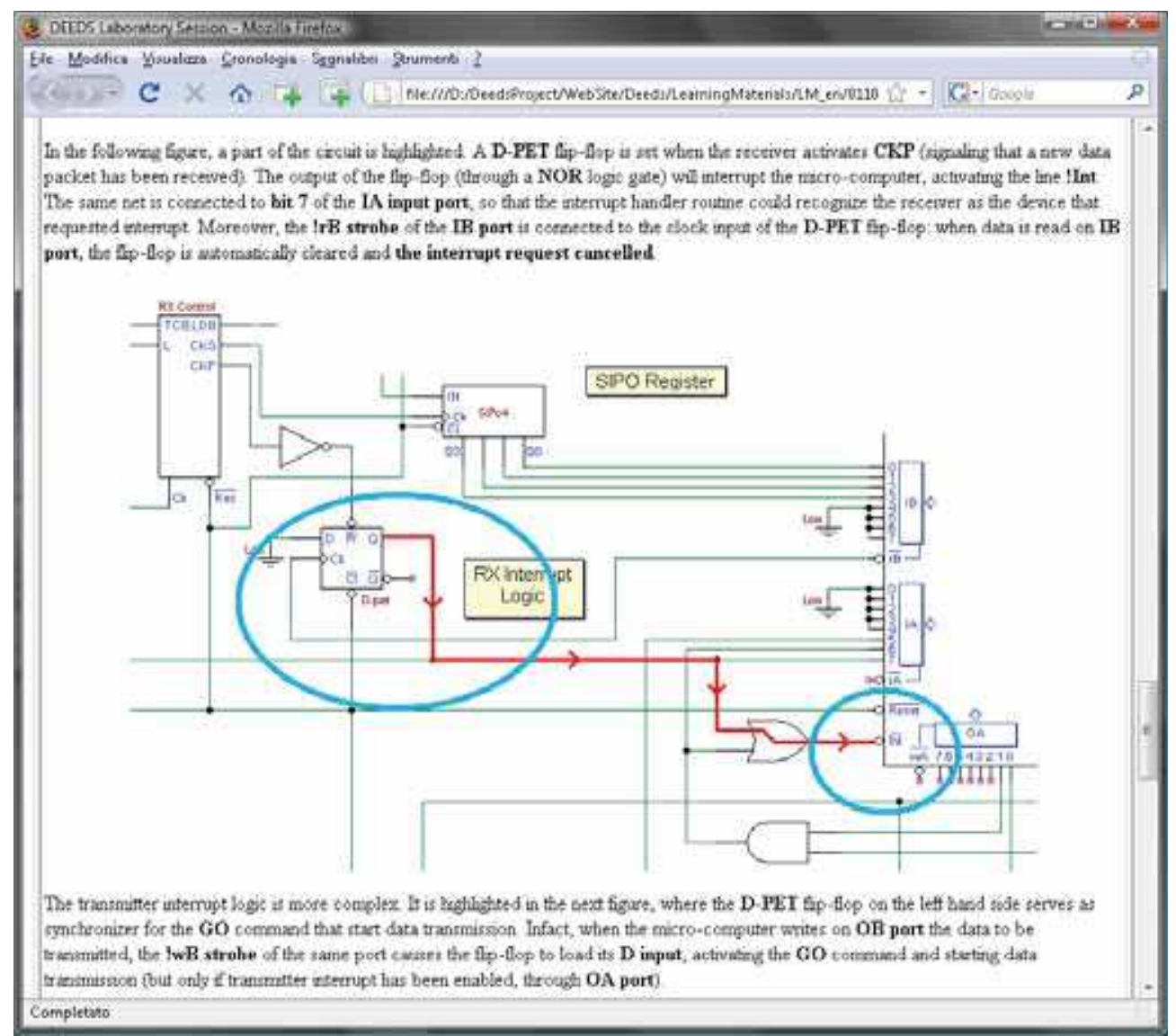

Fig. 12. The receiver interrupt logic explained to the student

The text continues with the explanation of the operation of the transmitter interrupt logic, that is more complex than the one of the receiver, because in this case the interrupt controller is (partially) programmable (Figure 13).

Data transmission needs to be started by a command, sent to the transmitter module, after the microcomputer has set up the info to be transmitted on its OB output port. The student must realize that, during the transmission of a data packet, the transmitter module is busy and can't accept another data. To solve the problem students needs to devise a hardware/software strategy to synchronize the transmission of the next packet. 
They could program the microcomputer to poll continuously the transmitter status, but this would result in a lack of performances. So the assignment suggests to program the interrupt logic to signal the microcomputer every time a data packet transmission has been completed. To do so, students must analyse carefully the proposed logic whose operation modes, summarized in a truth table in the text, depend from two control bits connected to the OA output port.

When the transmitter module requests interrupt, the microcomputer needs to recognize the source of interruption, reading the IA input port, as described before for the receiver. If the interrupt logic is programmed in the proper mode, when the microcomputer writes on the $\mathrm{OB}$ output port the data to be transmitted: a) the interrupt request is cleared, b) the transmitter operations are started, activating its GO command, and c) the new interrupt request is enabled (so that it will be generated when the transmission will end).

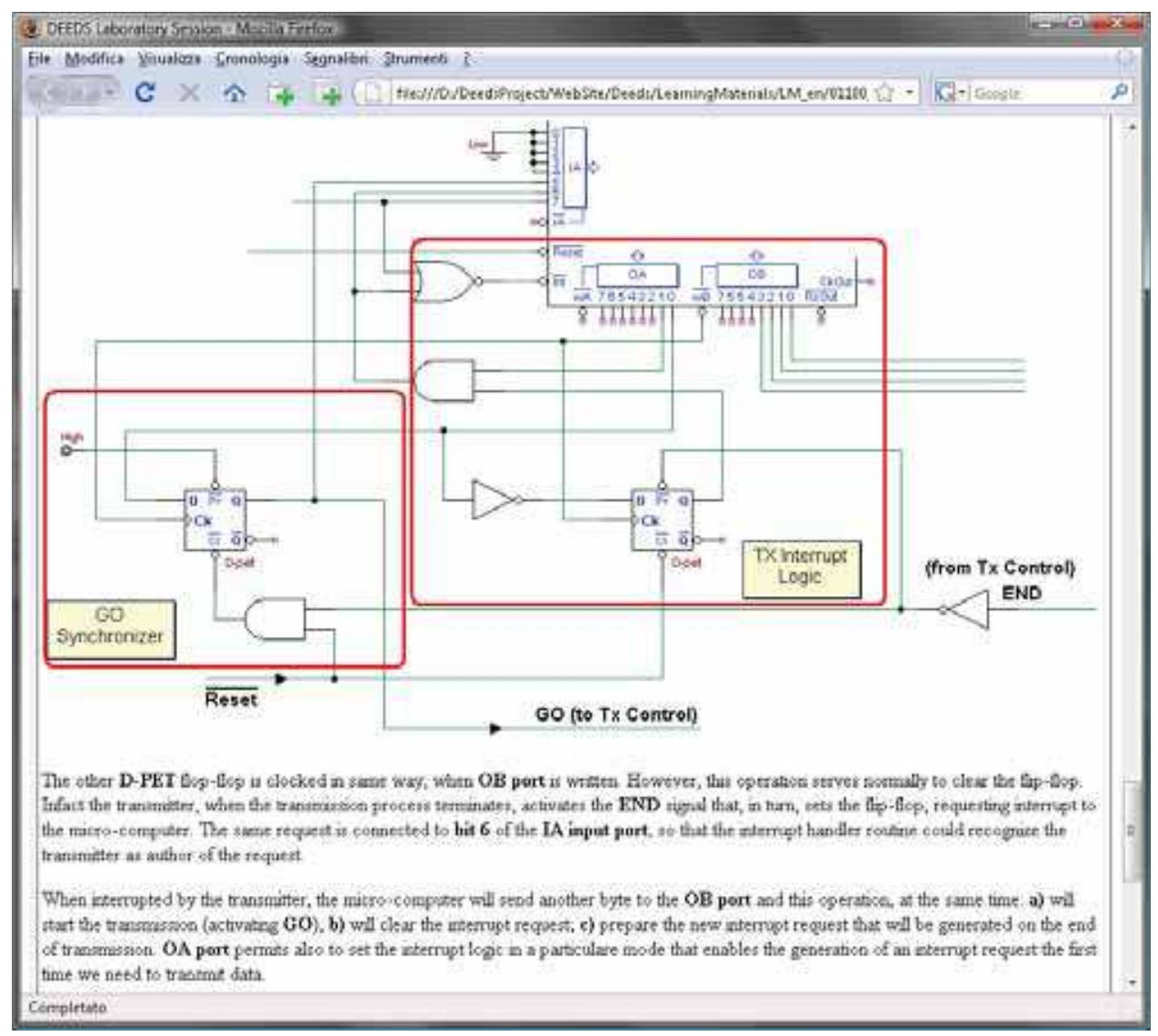

Fig. 13. The transmitter interrupt logic, highlighted in the assignment

At this point, the system analysis is over; the next stage for the student is the writing of the embedded processor code, in assembly language. The use of assembly language is a design choice for Deeds, because it allows a full understanding and control of the system. 
To write the code, starting from scratch, requires a full understanding of the interrupt operation. This task, even if it has been explained in details in the assignment, could be a difficult one for many students. So, we support them by providing a commented trace of the program, that can be downloaded directly in the d-McE. Obviously, students can choose to work independently or to use only parts of the given trace.

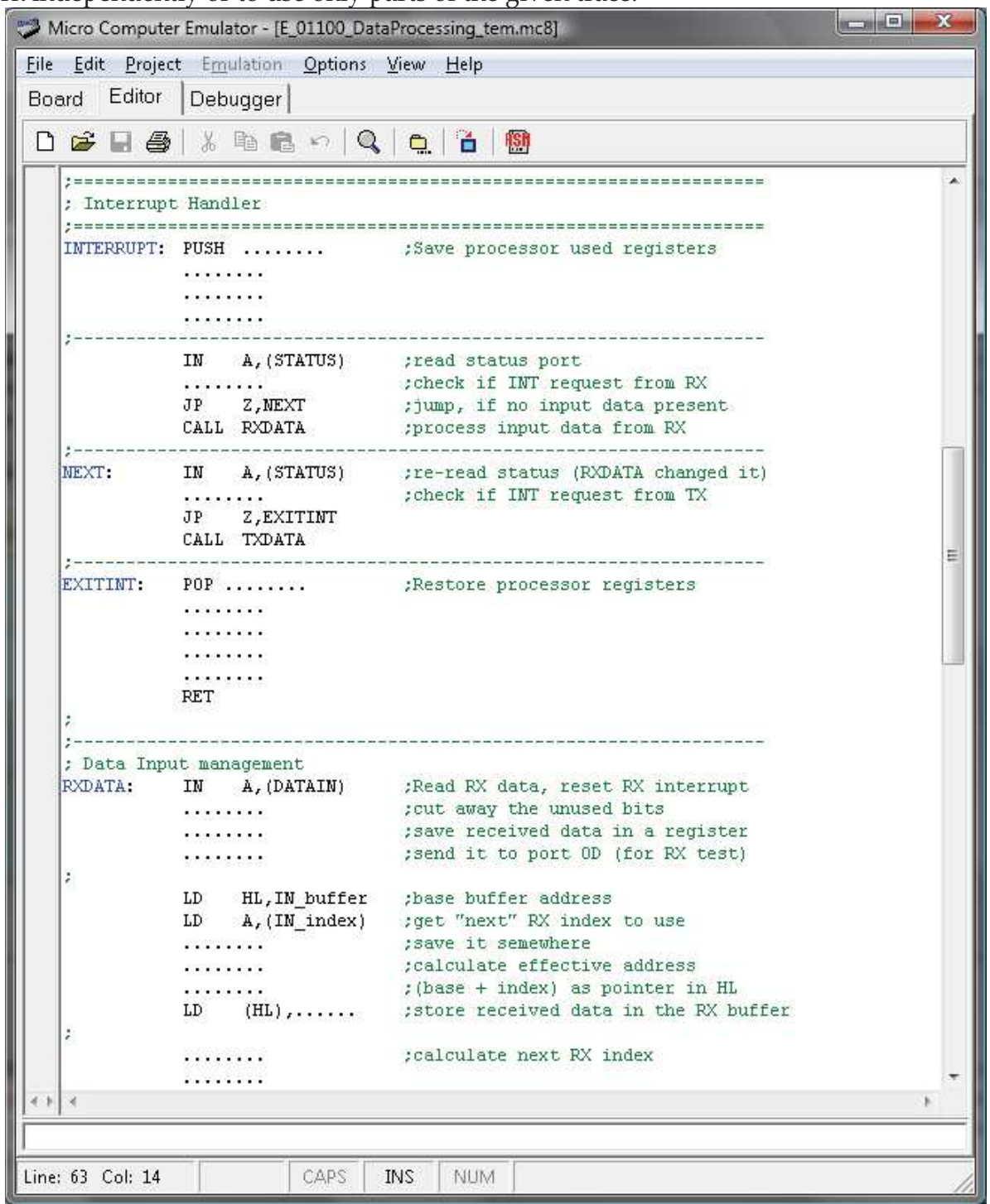

Fig. 14. The trace of the solution, downloaded in the d-McE 
Figure 14 shows a piece of the program trace, i.e. a partial solution where a few critical sequences of instructions are provided to help students to transfer concepts into practice with a reasonable effort.

Instead of a single trace, in other projects we provide several, graduated by difficulty so that the students may decide themselves how much help they need or want. It must be stressed that more guidance with the trace implies less freedom for the programmer.

Figure 15 shows an example of solution, produced by the student from the proposed trace.

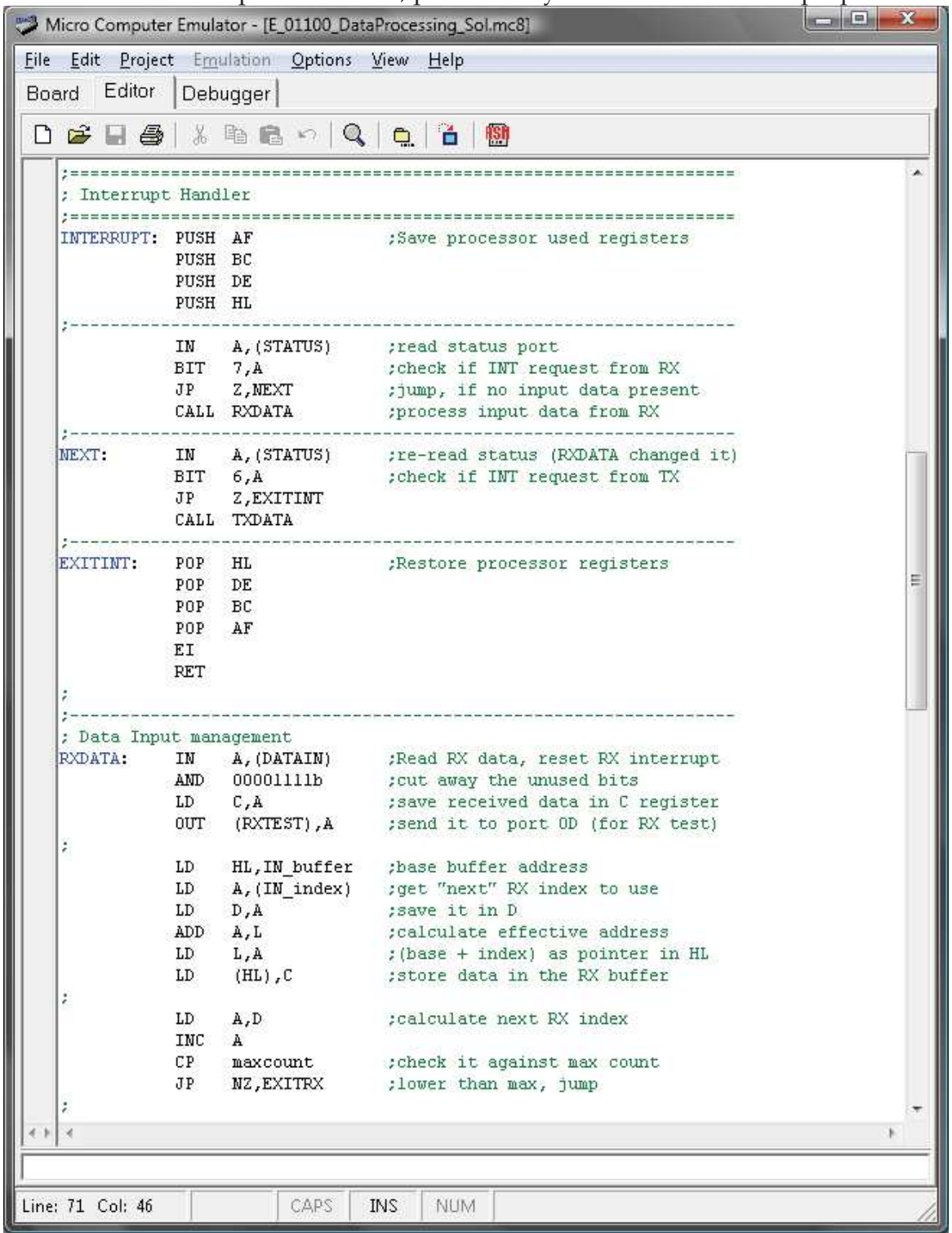

Fig. 15. The solution, completed by the student in the d-McE 


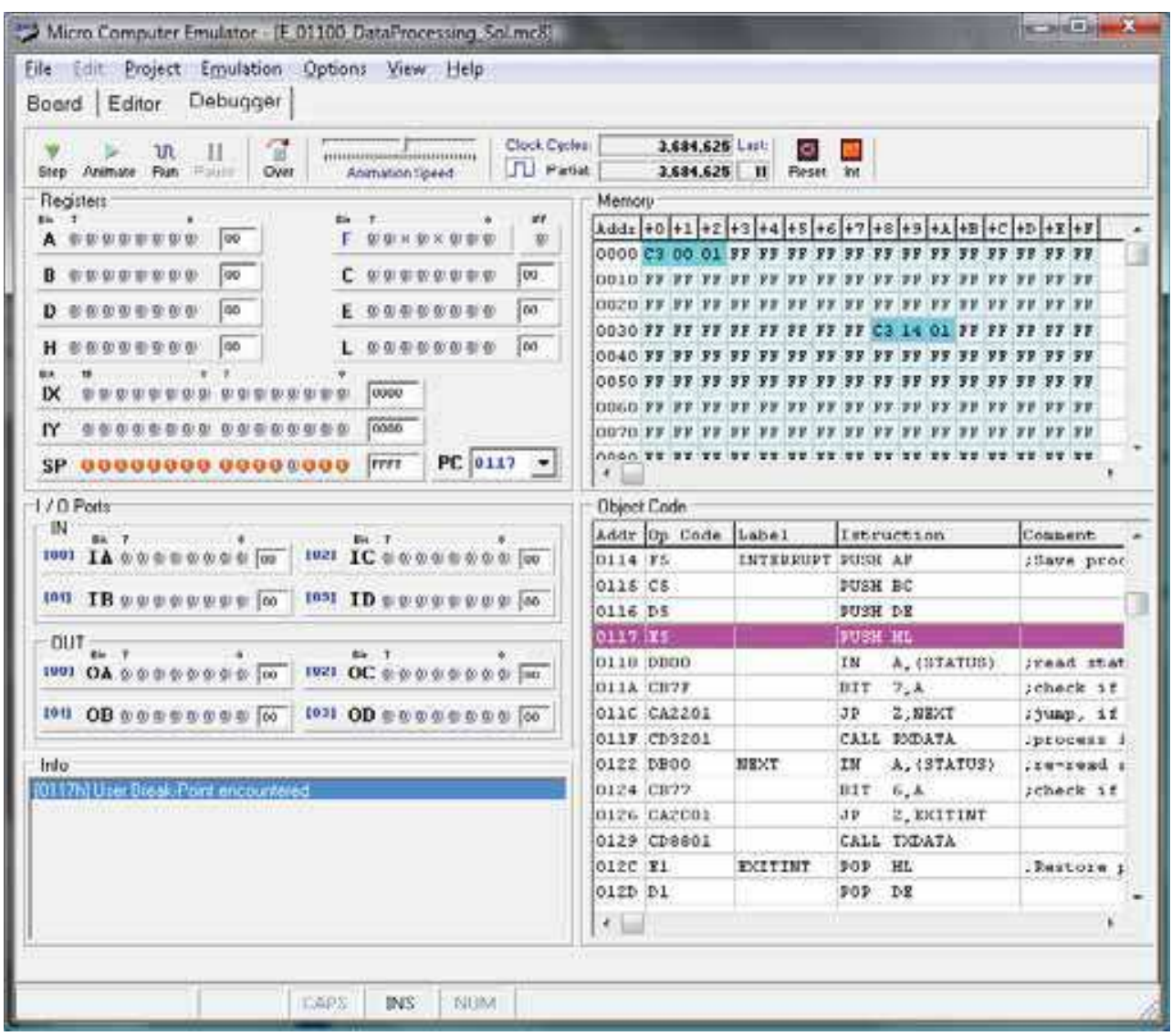

Fig. 16. Testing step by step the program code, in the interactive debugger of the d-McE

Before loading the program into the microcomputer flash ROM, a functional test could help in verifying its correctness, so the use of the emulation facilities included in the d-McE is suggested to the student. In Figure 16 the program is under test in the interactive debugger, where the learner could execute it in various modes, for example stepping the instructions manually one at time, or animating the process at an adjustable speed. The debugger is similar to the ones included in professional tools. By using it, the student can reach a high degree of confidence and control over the logic of the program, because all the elements in the microcomputer are observable and easily modifiable.

After completing the program and testing it in the d-McE, the student must load it in the flash ROM of the microcomputer component in the d-DcS schematic (seen before in Figure 11). The system, completed now of the microcomputer code, is ready for testing in the d-DcS (Figure 17), using the timing simulator (Figure 18). This is the final phase, in which the student is requested to validate all the elements, procedures, logic and algorithms that make up the functionality of the whole system. 


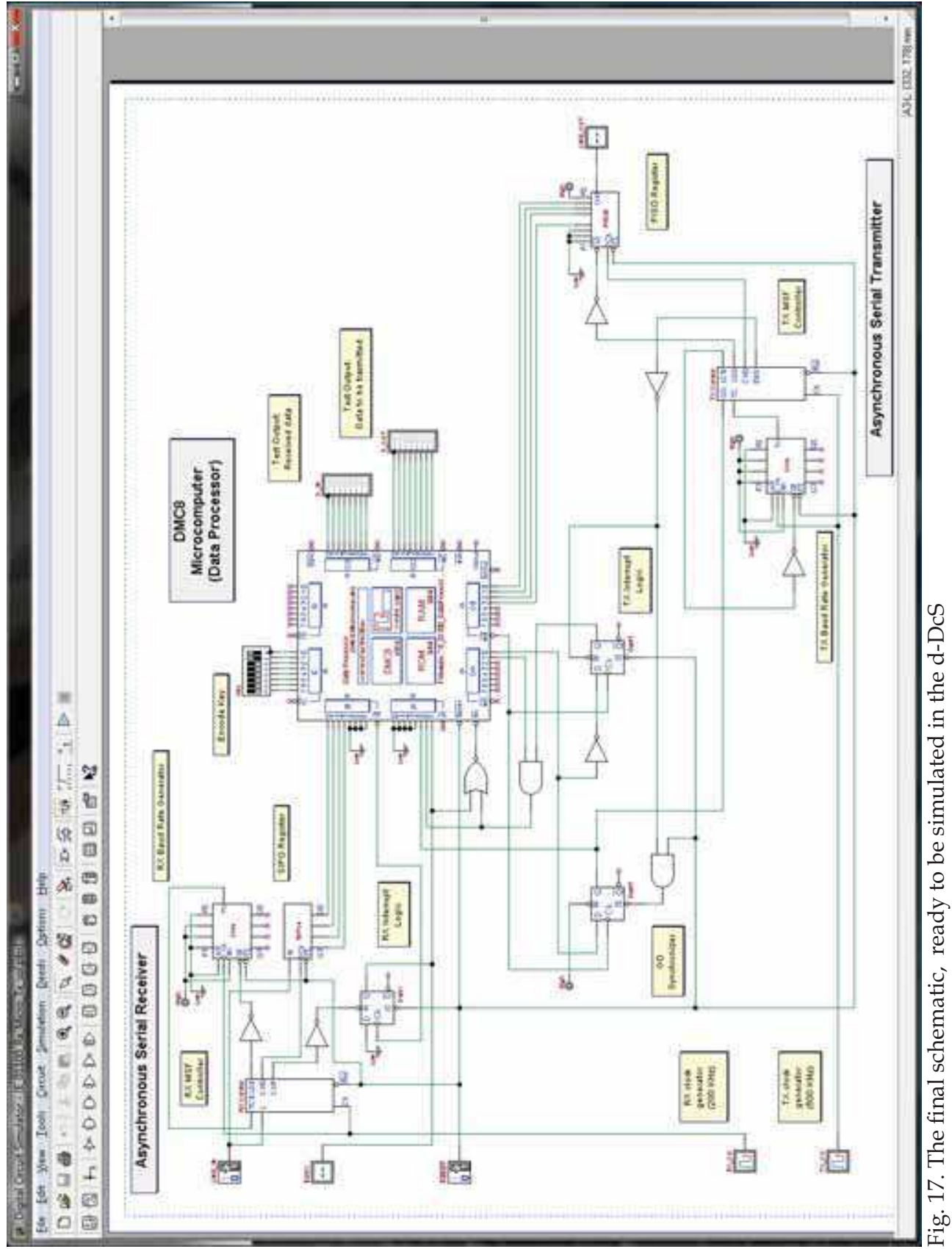




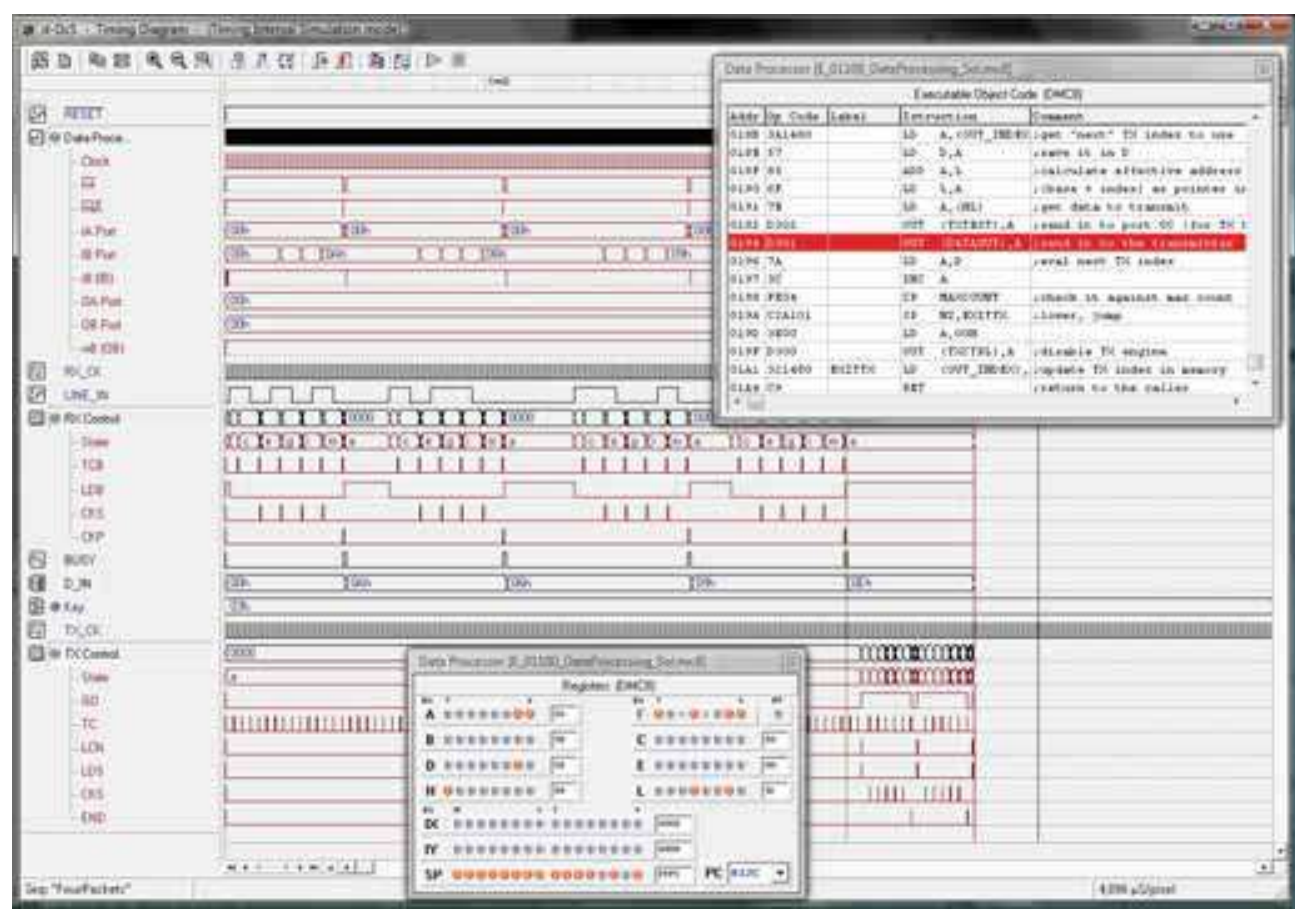

Fig. 18. Simulation and testing of the complete system

At this stage, usually, only motivated and hard-working students will make really good use of all the possibilities offered by the timing simulation; possibly only those people that are inclined to choose digital design as their job in real life. Most students, instead, will be satisfied simply if the system "seems" to operate, without trying to investigate the system behaviour thoroughly. Anyway, it is a good result if the student will reach the previous phase (the writing of the program and testing in the $\mathrm{d}-\mathrm{McE}$ tool).

\section{Conclusion}

The combination of Deeds and its associated learning material covers the foundations of the design of embedded systems. The experience has shown that the use of the simulation environment is an essential step to build in the students the necessary knowledge and skills for digital design. Deeds has now been used by thousands of students at the University of Genoa and other institutions. The development team is taking advantage of the continuous feedback from students and colleagues to enrich the collection of learning materials, to improve existing functionalities and to add new features. For instance, we are working on a new version of the digital simulator engine, using the inertial model to manage components delays instead of the transport model currently in use. 


\section{Appendix: tools for digital electronics}

The appendix provides links to a few commercially available (Table 1) and non-profit (Table 2) simulation and design tools for electronics. The lists are not exhaustive and the links may change or be no longer active.

\begin{tabular}{|l|l|}
\hline Altera & http://www.altera.com \\
\hline MacroSim & http://www.engineering-software.com/pr/addProd106.htm \\
\hline $\begin{array}{l}\text { MultiSim (Electronic } \\
\text { Workbench) }\end{array}$ & http://www.ni.com/academic/multisim \\
\hline OrCAD & http://www.cadence.com/products/orcad \\
\hline Proteus & http://www.labcenter.co.uk/index_uk.htm \\
\hline Tina Design Suite & http://www.designsoftware.com \\
\hline Xilinx & http://www.xilinx.com \\
\hline
\end{tabular}

Table 1. A few professional products often used in the educational field

\begin{tabular}{|l|l|}
\hline Circuit Shop & http://www.cherrywoodsystems.com/cshop1.htm \\
\hline Digital Simulator & http://www.mit.edu/people/ara/ds.html \\
\hline Digital Works & http:// www.spsu.edu/cs/faculty/bbrown/circuits/howto.html \\
\hline EasySim & http://www.research-systems.com/easysim/easysim.htm \\
\hline Logisim & http://ozark.hendrix.edu/ burch/logisim \\
\hline Digital WorkShop & http:// www.cise.ufl.edu/ fishwick/dig/DigSim.html \\
\hline WinLogiLab & $\begin{array}{l}\text { http://www.griffith.edu.au/professional-page/charles- } \\
\text { hacker/resources/winlogilab }\end{array}$ \\
\hline
\end{tabular}

Table 2. Partial list of non-profit simulators for digital electronics

\section{References}

Asumadu J. A. ; Tanner R. ; Fitzmaurice J. ; Kelly M. ; Ogunleye H. ; Belter J. \& Song Chin Koh (2005). A Web-Based Electrical and Electronics Remote Wiring and Measurement Laboratory (RwmLAB) Instrument, IEEE Transactions on Instrumentation and Measurement. Vol. 54, No. 1, (Feb. 2005) pp. 38-44, ISSN 00189456

Bagnasco A.; Chirico M. \& Scapolla A. M. (2005). A New and Open Model to Share Laboratories on the Internet. IEEE Transaction on Instrumentation and Measurement, Vol. 54, No. 3, (June 2005) pp. 1111-1117, ISSN 0018-9456

Bovone, A. ; Donzellini, G. ; Pedrotti, U. \& Ponta, D. (1999). A functional Finite State Machine simulator. Proceedings of CAEE'99, 5th International Conference on Computer Aided Engineering Education, pp. 85-90, Sofia, Bulgaria, September 1999, Technical University of Sofia, Sofia

Bruce, J.W.; Harden, J.C. \& Reese, R.B. (2004). Cooperative and progressive design experience for embedded systems, IEEE Transactions on Education, Vol. 47, No. 1, (Feb. 2004) pp. 83- 92, ISSN 0018-9359

Da Bormida, G. ; Ponta, D. \& Donzellini, G. (1997). Methodologies and Tools for Learning Digital Electronics. IEEE Transactions on Education, Vol. 40, No. 4, (November 1997) abstract p. 294, full paper on CD, ISSN 0018-9359 
Donzellini, G. \& Ponta, D. (2003). DEEDS: an E-Learning Environment for Digital Design, Proceedings of EUNITE 2003, European Symposium on Intelligent Technologies, Hybrid Systems and their implementation on Smart Adaptive Systems, abstract p.63, full paper on CD, ISBN 3-86130-194-6, Oulu, Finland, July 2003, Bürnberger, A. \& Gabrys, B. (Ed.), Oulu

Donzellini, G. \& Ponta, D. (2007, a). The electronic laboratory: traditional, simulated or remote? In: Advances on remote laboratories and e-learning experiences, Gomes, L. \& Garcia Zubia, J. (Ed.), pp. 223-246, University of Deusto, ISBN 978-84-9830-077-2, Bilbao

Donzellini, G. \& Ponta, D. (2007, b). A Simulation Environment for e-Learning in Digital Design. IEEE Trans. on Industrial Electronics, Vol. 54, Vo. 6, (Dec. 2007) pp. 30783085, ISSN 0278-0046

Donzellini G. \& Ponta, D. (2008). A Virtual Laboratory for Digital Design, International Journal of Online Engineering (iJOE), Vol. 4, No. 2, (2008), ISSN 1861-2121, Available: http://www.online-journals.org/i-joe

Garcia-Zubia J.; Lopez-de-Ipiña D.; Orduña P.; Hernandez U. \& Trueba I. (2006). Questions and Answers for Designing Useful WebLabs. International Journal of Online Engineering (iJOE), Vol. 2, No. 3, (2006), ISSN 1861-2121, Available: http://www.online-journals.org/i-joe

Gillet D.; Anh Vu Nguyen Ngoc \& Rekik Y. (2005), Collaborative web-based experimentation in flexible engineering education. IEEE Transactions on Education, Vol. 48, No. 4, (November 2005) pp. 696- 704, ISSN: 0018-9359

Gustavsson I. ; Zackrisson J. ; Åkesson H. ; Håkansson L. ; Claesson I. \& Lagö T. (2006). Remote Operation and Control of Traditional Laboratory Equipment, International Journal of Online Engineering (iJOE). Vol. 2, No. 1, (2006), ISSN 1861-2121, Available: http://www.online-journals.org/i-joe

Hacker, C. \& Sitte, R. (2004). Interactive teaching of elementary digital logic design with WinLogiLab. IEEE Transactions on Education, Vol. 47, No. 2, (May 2004) pp. 196- 203, ISSN 0018-9359

Markkanen, H.; Donzellini, G. \& Ponta, D. (2001). NetPro: methodologies and tools for Project Based Learning in Internet, Proceedings of ED-MEDIA 2001, World Conference on Educational Multimedia, Hypermedia E Telecommunications, pp. 1230-1235, ISBN 1880094-42-8, Tampere, Finland, June 2001, AACE, Tampere

Nooshabadi, S. \& Garside, J. (2006). Modernization of teaching in embedded systems design - an international collaborative project. IEEE Transactions on Education, Vol. 49, No. 2, (May 2006) pp. 254- 262, ISSN 0018-9359

Ponta, D. \& Scapolla A.M. (2007). Digital Design with KP-Lab. International Journal of Online Engineering (iJOE), Vol. 3, No. 3, (2007), ISSN 1861-2121, Available: http://www.online-journals.org/i-joe

Ponta, D. ; Donzellini, G. \& Markkanen, H. (2001). Electronic Systems Design: an experiment of Project Based Learning on Network. European Journal of Engineering Education, Vol. 26, No. 4, (December 2001) pp. 375- 390, ISSN 0304-3797

Zimmer T., Billaud M. \& Geoffroy D. (2006). A Remote Laboratory for Electrical Engineering Education. International Journal of Online Engineering (iJOE). Vol. 2, No. 3, (2006), ISSN 1861-2121, Available: http:/ / www.online-journals.org/i-joe 


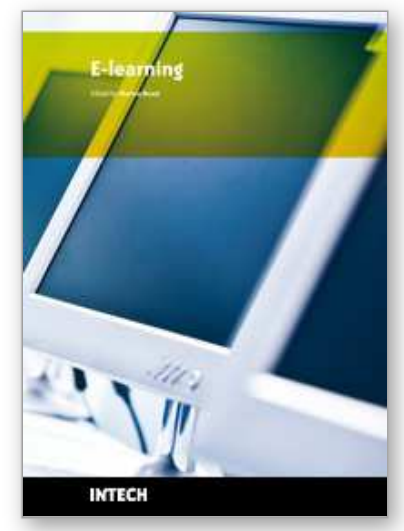

\author{
E-learning \\ Edited by Maja Jakobovic
}

ISBN 978-953-7619-95-4

Hard cover, 312 pages

Publisher InTech

Published online 01, February, 2010

Published in print edition February, 2010

E-Learning is a vast and complex research topic that poses many challenges in every aspect: educational and pedagogical strategies and techniques and the tools for achieving them; usability, accessibility and user interface design; knowledge sharing and collaborative environments; technologies, architectures, and protocols; user activity monitoring, assessment and evaluation; experiences, case studies and more. This book's authors come from all over the world; their ideas, studies, findings and experiences are a valuable contribution to enriching our knowledge in the field of eLearning. The book is divided into three sections. The first covers architectures and environments for eLearning, while the second part presents research on user interaction and technologies for building usable eLearning environments, which are the basis for realizing educational and pedagogical aims, and the final last part illustrates applications, laboratories, and experiences.

\title{
How to reference
}

In order to correctly reference this scholarly work, feel free to copy and paste the following:

Giuliano Donzellini and Domenico Ponta (2010). E-Learning Tool for Digital Design and Embedded System Training, E-learning, Maja Jakobovic (Ed.), ISBN: 978-953-7619-95-4, InTech, Available from:

http://www.intechopen.com/books/e-learning/e-learning-tool-for-digital-design-and-embedded-system-training

\section{INTECH}

open science | open minds

\section{InTech Europe}

University Campus STeP Ri

Slavka Krautzeka 83/A

51000 Rijeka, Croatia

Phone: +385 (51) 770447

Fax: +385 (51) 686166

www.intechopen.com

\section{InTech China}

Unit 405, Office Block, Hotel Equatorial Shanghai

No.65, Yan An Road (West), Shanghai, 200040, China 中国上海市延安西路65号上海国际贵都大饭店办公楼 405 单元 Phone: +86-21-62489820

Fax: $+86-21-62489821$ 
(C) 2010 The Author(s). Licensee IntechOpen. This chapter is distributed under the terms of the Creative Commons Attribution-NonCommercial-ShareAlike-3.0 License, which permits use, distribution and reproduction for non-commercial purposes, provided the original is properly cited and derivative works building on this content are distributed under the same license. 